\section{LA IMPLICACIÓN DE LAS FRUTAS Y HORTALIZAS EN LAS TOXIINFECCIONES ALIMENTARIAS Y LA RELEVANCIA DEL ESTADO FISIOLÓGICO DE LAS BACTERIAS}

\author{
Pilar Truchado \\ Centro de Edafología y Biología Aplicada del Segura (CEBAS) \\ Consejo Superior de Investigaciones Científicas \\ ORCID iD: https://orcid.org/0000-0002-9517-6740 \\ ptruchado@cebas.csic.es \\ Ana Allende \\ Centro de Edafología y Biología Aplicada del Segura (CEBAS) \\ Consejo Superior de Investigaciones Científicas \\ ORCID iD: https://orcid.org/0000-0002-5622-4332 \\ aallende@cebas.csic.es
}

Cómo citar este artículo/Citation: Truchado, P. y Allende, A. (2020). La implicación de las frutas y hortalizas en las toxiinfecciones alimentarias y la relevancia del estado fisiológico de las bacterias. Arbor, 196 (795): a541. https://doi.org/10.3989/ arbor.2020.795n1005

Recibido: 26 febrero 2019. Aceptado: 29 octubre 2019.

RESUMEN: Las frutas y hortalizas han sido siempre noticia debido principalmente a sus propiedades beneficiosas para la salud. Sin embargo, cada vez más ocupan titulares debido a su implicación en toxiinfecciones alimentarias. Por este motivo, desde 2008, las frutas y hortalizas frescas son consideradas por muchos organismos internacionales como un alimento de riesgo. Uno de los principales problemas microbiológicos de las hortalizas de hojas son las bacterias entéricas que pueden adherirse rápidamente al tejido durante el cultivo, coexistir con las bacterias epífitas y persistir por largos periodos de tiempo. La prevalencia de microorganismos patógenos en las frutas y hortalizas es baja $(<1 \%)$ y la cuantificación de las bacterias patógenas o de microorganismos indicadores generalmente muestra niveles muy bajos, lo que no justificaría el elevado número de alertas microbiológicas asociadas a este tipo de productos. Sin embargo, existen dudas sobre si los recuentos obtenidos utilizando las técnicas convencionales son capaces de reflejar realmente todos los microorganismos presentes en el producto vegetal, así como en el agua de riego y en el suelo. Varios estudios han demostrado que cuando las bacterias son sometidas a distintos factores de estrés entran en un estado temporal de baja actividad metabólica en el cual las células pueden persistir durante largos periodos de tiempo sin división celular, llamado estado de latencia o viable pero no cultivable (VBNC). La relevancia que el estado fisiológico de las bacterias puede tener en el desarrollo de toxiinfecciones alimentarias causadas por las frutas $y$ hortalizas es un tema de gran interés que está atrayendo más y más la atención de los investigadores.

PALABRAS CLAVE: vegetales frescos; viable no cultivable; seguridad alimentaria; bacterias patógenas; producción primaria

\section{RELEVANCE OF FRESH FRUITS AND VEGETABLES IN FOODBORNE OUTBREAKS AND THE SIGNIFICANCE OF THE PHYSIOLOGICAL STATE OF BACTERIA}

Copyright: (C) 2020 CSIC. Este es un artículo de acceso abierto distribuido bajo los términos de la licencia de uso y distribución Creative Commons Reconocimiento 4.0 Internacional (CC BY 4.0).

ABSTRACT: Fruits and vegetables have always been in the news, mainly because of their beneficial properties for human health. However, they increasingly occupy headlines due to their involvement in foodborne outbreaks. This is the reason why, since 2008, many international organizations consider fruit and vegetables risky food. One major microbiological concern regarding the safety of leafy greens is that pathogenic microorganisms are able to adhere to and survive on plant tissue during cultivation and processing, coexist with epiphytic bacteria and persist for long periods of time. The prevalence of pathogenic microorganisms in fruits and vegetables is low $(<1 \%)$ and enumeration of pathogenic or indicator bacteria usually show very low numbers, which do not explain the high number of microbiological alerts associated with this types of products. However, concerns have been raised regarding how representative the enumeration of bacteria using plate count techniques may be. Several studies have shown that when bacteria are subjected to different stresses, they enter into a temporary state of low metabolic activity in which the cells can persist for long periods of time without cell division, called latency or viable but non-culturable (VBNC). The significance that the physiological state of bacteria might have in the development of foodborne diseases caused by fruits and vegetables is getting a lot of attention and much research is now focused on this topic.

KEYWORDS: fresh produce; viable but non cultivable; food safety; pathogenic bacteria; primary production 


\section{INTRODUCCIÓN}

La seguridad alimentaria sigue representando una de las principales preocupaciones en el campo de la salud pública debido principalmente al considerable número de toxiinfecciones transmitidas por los alimentos. En general, se estima que en el mundo se producen cerca de 9.4 millones de toxiinfecciones alimentarias (TIAs), las cuales causan 55.961 hospitalizaciones y 1.351 muertes al año. Estas TIAs son provocadas por muchos tipos de microorganismos pero fundamentalmente por bacterias como son Campylobacter, Salmonella, Escherichia coli patogénica y Listeria monocytogenes entre otras (Ding et al., 2017). Los productos vegetales frescos suponen un importante vehículo de transmisión de estas bacterias y su incidencia en humanos ha aumentado en los últimos años. Muchos son los factores que se han identificado como responsables de ese incremento en el número de TIA asociadas a los alimentos frescos, entre las que se pueden mencionar los cambios en la alimentación y en el estilo de vida, que ha provocado un aumento en el consumo de vegetales frescos, así como la mejora de los programas de vigilancia y las técnicas de detección de los microorganismos patógenos (EFSA, 2013; véase también European Commission Notice No. 2017/C 163/01).

Las autoridades competentes, tales como la Comisión Europea (CE) en Europa y la Food and Drug Administration (FDA) en Estados Unidos, han elaborado guías de recomendaciones y legislación en las que se incluye la monitorización de las aguas de riego, con el fin de evitar riesgos microbiológicos que puedan provocar TIA asociadas a productos vegetales. Asimismo, la legislación europea incluye límites microbiológicos para las frutas y hortalizas listas para su consumo, lo que hace necesario detectar y cuantificar los microorganismos patógenos e indicadores que pueden estar presentes en los productos vegetales (véase Commission Regulation (EC) No 2073/2005 of 15 November 2005; European Commission Notice No. 2017/C 163/01; FSMA Final Rule on Produce Safety).

Tradicionalmente, para detectar y cuantificar la presencia de bacterias patógenas o, en su lugar, microorganismos indicadores de contaminación fecal, se utilizan técnicas dependientes de cultivo. Sin embargo, numerosos estudios han evidenciado que los recuentos basados en métodos de cultivo en placa no dan una buena estimación del número real de microorganismos presentes en los alimentos. Durante la producción y procesado, los alimentos se someten a numerosas etapas que pueden constituir un estrés para las bacterias. Las bacterias pasan entonces de un estado totalmente activo y cultivable a un estado de latencia, denominado viable pero no cultivable (VBNC). Los cambios de temperatura, el uso de desinfectantes y los tratamientos con luz-UV son algunos de factores causantes de estrés a las bacterias y que los estudios científicos han asociado con una inducción al estado VBNC de los microorganismos presentes en los alimentos (Ding et al., 2017; Dinu y Bach, 2011; Zhang, Ye, Lin, Lv y Yu, 2015). El estado VBNC fue descubierto en el año 1982 por Xu et al. (1982), y define a aquellas bacterias que no pueden desarrolladas en un medio de cultivo pero que siguen metabólicamente activas. A pesar de que estas bacterias no son cultivables, pueden representar un peligro para los consumidores, ya que hay evidencias científicas de que estas bacterias pueden revertir este estado a un estado metabólicamente activo cuando se encuentran en condiciones favorables de crecimiento, pudiendo desarrollar su patogenicidad (Highmore, Warner, Rothwell, Wilks. y Keevil, 2018). Hasta el momento, no existes evidencias científicas que confirmen que los brotes de TIA descritos en los últimos años hayan sido provocados por bacterias patógenas en estado de VBNC. Sin embargo, algunos estudios han intentado demostrar que la presencia de bacterias patógenas en estado VBNC han podido ser la causa de algunas de las TIA. Por ejemplo, Makino et al. (2000) establece una relación entre un brote de TIA ocurrido en Japón asociado al consumo de salmón y la presencia de la bacteria Escherichia coli 0157:H7 en estado VBNC debido al proceso de salado al que se somete el salmón.

Con respecto a las TIA ocurridas por el consumo de vegetales, Zhao, Zhong, Wei, Lin y Ding (2017), sugieren que Escherichia coli 0104:H4, responsable de la toxinfección en Alemania en el año 2011, no pudo ser detectada ni aislada de la fuente de contaminación porque se encontraba en un estado VBNC. Esta teoría está apoyada por las investigaciones realizadas por Aurass, Prager y Flieger (2011) que confirmaron que la cepa de Escherichia coli 0104:H4 que generó la TIA en Alemania entró en un estado de VBNC por los iones de cobre que posee el agua potable de esa zona, y que cuando el estrés remitió, la bacteria resucitó manteniendo su patogenicidad. Además, también se ha demostrado que la bacteria Escherichia coli 0157:H7 en estado VBNC, continúa expresando sus factores de virulencia una vez es inoculada sobre lechuga (Dinu y Bach, 2011). Por lo tanto, existe una necesidad de investigar la relevancia en la seguridad alimentaria del estado fisiológico de las bacterias, y más concretamente qué capacidad de patogenicidad tienen las 
bacterias que se encuentran en el estado VBNC en los alimentos. Asimismo, se necesita más investigación centrada en el desarrollo y optimización de métodos rápidos de detección que nos permitan determinar el estado fisiológico de las bacterias para poder mejorar la seguridad alimentaria.

\section{CARACTERÍSTICAS DE LAS BACTERIAS EN ESTADO CULTIVABLE Y VIABLE NO CULTIVABLE (VBNC)}

Varios estudios han demostrado que cuando las bacterias, incluidas las bacterias patógenas de alimentos, son sometidas a un estrés entran en un estado temporal de baja actividad metabólica en el cual las células pueden persistir durante largos periodos de tiempo sin división celular, llamado latencia (Oliver, 2010). En las bacterias no esporuladas existen dos estados de latencia: las células viables no cultivables (VBNC) y las células llamadas persistentes (persister cells) (Ayrapetyan, Williams, Baxter y Oliver, 2015). Aunque comparten algunas similitudes, las células VBNC no se dividen, sino que mantienen sus membranas celulares intactas, continúan con la expresión génica y tienen la capacidad de convertirse en cultivables una vez resucitadas. Sin embargo, las condiciones y los medios de cultivo utilizados en la microbiología clásica no cumplen con los requisitos de estos organismos para reanudar su crecimiento inmediatamente (Zhao et al., 2017). La mayoría de las especies bacterianas son capaces de entrar en un estado VBNC cuando se encuentran en condiciones ambientales adversas, lo que incluye la exposición a biocidas que son utilizados frecuentemente en la industria alimentaria, lo que indica que el estado VBNC puede ser una fase habitual en el ciclo de vida de la bacteria (Oliver, 2005). Por otro lado, las células persistentes son células de crecimiento lento o subpoblaciones que no crecen dentro de un cultivo y que poseen tolerancia a distintos compuestos antimicrobianos, por lo que pueden sobrevivir a los mismos, mientras que el resto de la población sigue siendo sensible. Estas bacterias resistentes son capaces de reanudar el crecimiento cuando se encuentran en un medio que dispone de los nutrientes necesarios y las condiciones adecuadas para el mismo (Nyström, 2003).

Por lo tanto, las bacterias en estado VBNC se caracterizan principalmente por: (i) mantener la integridad celular; (ii) poseer alguna forma de actividad celular medible (Lai, Chen, Lin, Chang y Wong, 2009); (iii) tener la capacidad de recuperarse (Anuchin et al., 2009); (iv) responder a estímulos externos que se demuestran mediante la expresión génica (Kell,, Kaprelyants, Weichart, Harwood y Barer, 1998); (v) tener baja actividad metabólica (Oliver, 2005); (vi) presentar enanismo (Costa et al., 1999); (vii) tener reducido el transporte de nutrientes; (viii) tener un alto nivel de ATP y mostrar un alto nivel de potencial de membrana (Signoretto, Lleo y Canepari, 2002); (ix) presentar modificaciones en la composición de ácidos grasos de las membranas citoplasmáticas (Day y Oliver, 2004); así como $(x)$ tener una mayor resistencia a los antibióticos debido a una actividad metabólica más baja (Oliver, 2010).

Como hemos indicado anteriormente, el estado VBNC puede ser desencadenado por circunstancias de estrés como duras condiciones ambientales (Oliver, 2010), escasez de nutrientes (Cook y Bolster, 2007) temperaturas extremas (Besnard, Federighi, Declerq, Jugiau y Cappelier, 2002), fuertes cambios de $\mathrm{pH}$ o salinidad (Cunningham, O'Byrne y Oliver, 2009); estrés osmótico (Asakura et al., 2008), disponibilidad de oxígeno (Kana et al., 2008; Mascher, Hase, Moenne-Loccoz y Défago, 2000), y daño o perdida de componentes esenciales de la célula incluido el ADN por la exposición a metales pesados, conservantes o luz UV (Fakruddin, Bin Mannan y Andrews, 2013). Además, durante el procesado de alimentos, existen numerosos factores que pueden inducir a las células al estado VBNC tales como los tratamientos térmicos, el uso de antibacterianos como fagos lisogénicos, autolisinas y los procesos de desinfección (Nicolò y Guglielmino, 2012; Oliver, 2010).

Pese a todos los estudios que se han llevado a cabo con el objetivo de esclarecer la relevancia de este estado en la seguridad alimentaria, el estado VBNC continúa estando en entredicho debido a las dificultades que existen para diferenciar las células VBNC y las células latentes a través de reanimación y estudios fenotípicos. Sin embargo, recientemente, avances en las técnicas moleculares que se pueden utilizar con este fin están generando información muy valiosa que va a poder ser utilizada para clarificar la relevancia del estado VBNC.

\section{MÉTODOS DE ANÁLISIS CAPACES DE DIFERENCIAR EL ESTADO FISIOLÓGICO DE LAS BACTERIAS: ESTADO CULTIVABLE Y ESTADO VIABLE PERO NO CULTIVABLE (VBNC)}

\subsection{Bacterias cultivables}

Los métodos convencionales de cultivo en placa son utilizados de forma rutinaria y permiten determinar la cultivabilidad de las células. Aquellas bacterias que son capaces de formar una colonia en un medio de cultivo sólido se denominan cultivables. Estudios previos han estimado que, por lo general, solo el $10 \%$ de 
las bacterias que se encuentran en los productos vegetales frescos son cultivables (Rastogi et al., 2012). Por ese motivo, los estudios centrados en determinar el impacto que los distintos procesos tienen en la carga microbiana de productos vegetales y que solo utilizan los métodos de cultivo en placa, no pueden considerarse representativos de la población microbiana presente en este tipo de productos. Existen múltiples medios de cultivo que permiten cuantificar grupos genéricos de bacterias, como es el caso de los medios nutritivos de cultivo para bacterias aerobias totales, pero también existen medios de cultivo selectivos que permiten cuantificar grupos bacterianos específicos.

\subsection{Bacterias viables no cultivables (VBNC)}

Los métodos utilizados para detectar VBNC se basan principalmente en dos de las características claves de las mismas: la viabilidad y su cultivabilidad. Por lo tanto, para poder detectar VBNC en una muestra, el primer paso es el uso de la técnica de recuento en placa para confirmar que cantidad de células se encuentran en un estado cultivable, seguido de la estimación de células viables.

Para determinar la viabilidad celular es necesario el empleo de metodología más avanzada de biología molecular, citometría de flujo o microscopia electrónica.

\subsubsection{Métodos de tinción}

Una de las técnicas más comunes para visualizar la fisiología de la bacteria y su viabilidad es el uso de la tinción de células usando diferentes colorantes funcionales. Estos colorantes poseen ciertas propiedades que les permiten entrar en la célula, unirse a ciertas regiones de la célula e incluso ser metabolizados. En general suelen emitir fluorescencia que da información sobre la fisiología de la célula. La metodología más utilizada para determinar la viabilidad celular es la media de la integridad de la membrana utilizando el kit conocido como LIVE/DEAD BacLight Bacterial viability. Este método se basa en que las células muertas tienen la pared celular rota o comprometida y en las células viables se mantiene intacta (Oliver, 2005). Este sistema es un método rápido de tinción que utiliza dos marcadores fluorescentes, el SYTO9 y el yoduro de propidio, que se diferencian por sus características espectrales y su capacidad de penetrar en las células bacterianas viables.

El fluorocromo SYTO9 tiñe todas las células, independientemente del estado de su membrana citoplasmática. Por el contrario, el yoduro de propidio penetra solo en las células que tienen la membrana dañada, causando una reducción en la intensidad fluorescente del SYTO9 cuando ambos marcadores están presentes. Por tanto, las células que tienen la membrana citoplasmática intacta se tiñen de verde y se considerarán viables mientras que las bacterias que tienen dañada la membrana se tiñen de rojo y se considerarán no viables. La diferenciación por color para determinar la viabilidad celular se realizará con la ayuda de un microscopio de fluorescencia o un citómetro de flujo (Aurass et al., 2011; Berney et al., 2007). Sin embargo, la detección por citometría de flujo se considera una técnica más precisa que el uso del microscopio de epifluorescencia (Sieracki, Cucci y Nicinnski, 1999). Otros tintes dobles que también permiten diferenciar bacterias viables de bacterias muertas son el naranja de acridina y el CTC con 4,6-diamino-2 fenil indol (DAPI). El naranja de acridina se une al ARN, tiñendo de rojo las bacterias viables y de verde las muertas (Anvarian, Smith y Overton, 2016). En el método CTC combinado con DAPI, la viabilidad celular se distingue por el color rojo de las células (Besnard, Federighi y Cappelier, 2000; Winkelströter y De Martinis, 2015).

En los últimos años la citometría de flujo está siendo muy empleada en la microbiología de alimentos para realizar estudios sobre la funcionalidad bacteriana, detectar poblaciones bacterianas o para detectar la presencia de patógenos en el alimento (Bridier, Hammes, Canette, Bouchez y Briandet, 2015). Concretamente en alimentos vegetales algunos estudios ya han demostrado el efecto que algunas etapas del procesado tienen sobre el estado fisiológico de las bacterias utilizando la citometría de flujo en combinación con el uso de marcadores fluorescentes. Anvarian et al. (2016) estudió el efecto que la etapa de clarificación del zumo de naranja tiene sobre la inducción al estado de VBNC de Escherichia coli K-12. Tamburini, Foladori, Ferrentino, Spilimbergo y Jousson (2014) evaluaron la capacidad de inactivación bacteriana de la tecnología de conservación de dióxido de carbono a alta presión inoculando zanahoria cortada con Escherichia coli. Estos autores observaron que los tratamientos aplicados no eran capaces de inhibir completamente a la población bacteriana sino que, por el contrario, en una parte de la población se inducía un estado transitorio de VBNC.

\subsubsection{Métodos moleculares}

Muchas han sido las estrategias moleculares que se han descrito para diferenciar células VBNC de células muertas. Entre ellas, se encuentra la cuantificación del ARNm, como un indicador de la viabilidad celular, mediante la reacción en cadena de la polimerasa 
a tiempo real (Real time polymerase chain reaction), qPCR para su amplificación (Fischer-Le Saux, HervioHeath, Loaec, Colwel y Pommepuy, 2002). Sin embargo, hay que tener en cuenta que el ARNm tiene una vida muy corta y es muy lábil, lo que hace que incremente el riesgo de degradación de la molécula durante la extracción. Por ello, el uso de métodos basados en la detección del ADN mediante qPCR está mucho más extendido en la literatura científica. Sin embargo, hay que tener en cuenta que esta metodología adolece de la capacidad para diferenciar células vivas y muertas. Para poder subsanar este inconveniente se han desarrollado métodos alternativos que incorporan pretratamientos a la muestra con agentes colorantes tales como bromuro de etidio monoazide (EMA) o bromuro de propidio monoazide (PMA), que en combinación con la técnica qPCR permiten la identificación y cuantificación de las células viables (Nocker y Camper, 2009). Los colorantes utilizados son capaces de penetrar de manera selectiva en las membranas de las células que tienen la pared celular comprometida y se unen covalentemente al ADN mediante fotolisis, utilizando una fuente de luz visible, lo que evita la amplificación del ADN de las bacterias muertas en la posterior amplificación durante la qPCR (véase figura 1). Hay que destacar que algunos estudios han publicado que el tratamiento del ADN utilizando EMA no es del todo efectivo ya que no consigue una buena diferenciación entre las bacterias viables y las muertas. Por ese motivo, la mayoría de los estudios recomienda el uso del colorante PMA (Fittipaldi, Nocker y Codony, 2012). Por otro lado, la utilización del colorante PMA para la detección de células viables de bacterias patógenas presentes en el tejido vegetal ha sido ampliamente demostrada en estudios a escala de laboratorio (Dinu y Bach, 2011; Elizaquível, Sánchez y Aznar, 2012). Sin embargo, pocos estudios se han centrado en validar o demostrar el uso del PMA-qPCR para detectar la presencia de VBNC en productos vegetales en condiciones reales (Moyle, Harris y Marco, 2013; Truchado, Gil, Kostic y Allende, 2016). El estudio realizado por Truchado et al. (2016) validó el empleo de la técnica PMA-qPCR para detectar la presencia de Escherichia coli genérica en ensayos realizados en campos comerciales de lechuga en diferentes matrices, como es el agua de riego y el material vegetal. Recientemente Tombini Decol et al. (2019) han confirmado que la aplicación de la metodología descrita resulta adecuada para la detección y cuantificación de células de Escherichia coli en estado VBNC presentes en lechugas pigmentadas.

Es importante tener en cuenta que el combinado del PMA y la qPCR es exclusivo para células muertas que tienen la pared celular comprometida, por lo que la presencia de células muertas con la pared celular intacta podría ser causa de una sobreestimación del número de células viables (Nkuipou-Kenfack, Engel, Fakih y Nocker, 2013; Nocker y Camper, 2009). Para mejorar la detección de células viables no cultivables por qPCR, algunos autores han propuesto el uso de la amplificación isotérmica mediada por bucle (LAMP) o el tratamiento con ácido desoxicólico (DC) antes de la aplicación del PMA. El uso de PMA-LAMP se describe como un método rápido, sencillo y preciso con una alta sensibilidad y especificidad para detectar y cuantificar células viables de bacterias patógenas alterantes presentes en los alimentos, tales como Listeria, Escherichia coli patogénica y Salmonella (Fang et al., 2018; Wan et al., 2012; Zhao et al., 2013). Respecto al tratamiento con DC antes del PMA, los resultados muestran que el tratamiento previo con DC facilitado la penetración del PMA en las células muertas o en las células dañadas, reduciendo los resultados falsos positivos (Wang et al., 2014; Zhou et al., 2017). Aunque estas técnicas aún no han sido validadas para la

Figura 1. Esquema de amplificación de bacterias viables no cultivables utilizando tintes que se adhieren al DNA
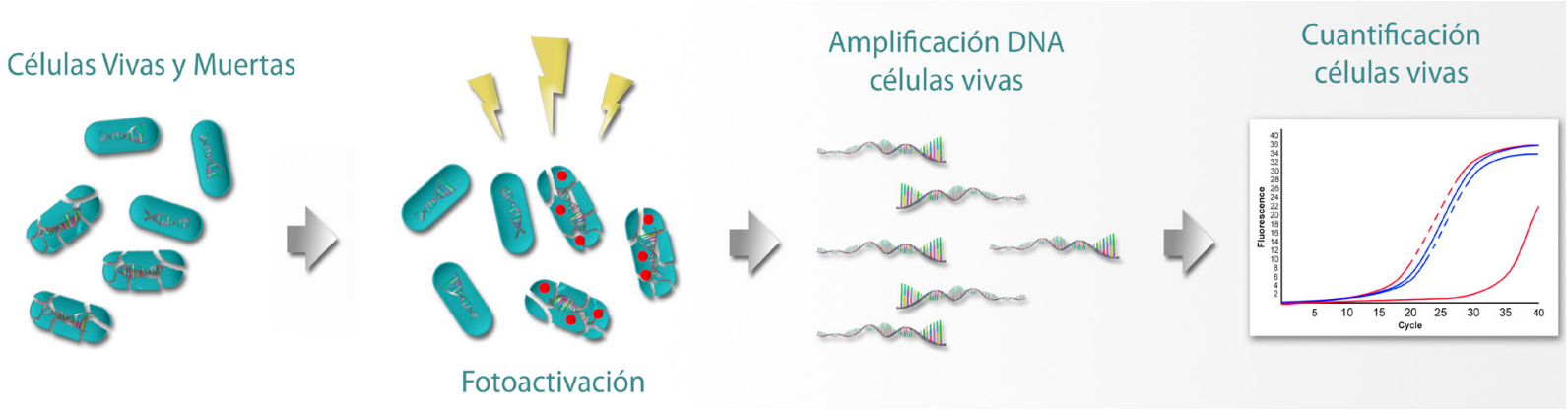

Fuente: elaboración propia 
detección de VBNC en vegetales, parecen ser técnicas prometedoras que hay que tener en cuenta para mejorar la detección de las VBNC en el tejido vegetal.

\section{LA IMPORTANCIA DEL ESTADO VBNC EN LA SEGU- RIDAD ALIMENTARIA DE LOS PRODUCTOS VEGETALES}

La no culturabilidad de las bacterias en el estado VBNC constituye un problema para la seguridad alimentaria y para la salud pública, ya que alimentos que a priori pueden parecer libres de bacterias patógenas pueden contener células en estado VBNC, capaces de resucitar y de causar la enfermedad. Esto es debido a que las células VBNC no son detectadas mediante las técnicas convencionales de cultivo en placa. En la literatura científica existen opiniones controvertidas con respecto a si las bacterias que se encuentran en estado VBNC todavía retienen su patogenicidad. Por un lado, existen evidencias científicas que indican que algunas bacterias patógenas en estado VBNC pueden expresar sus factores de virulencia, por lo que su capacidad de infección puede recuperarse si el estado VBNC es revertido (Anderson et al., 2004; Highmore et al., 2018; Pommepuy et al., 1996). Sin embargo, otros estudios apuestan por que los microorganismos en el estado VBNC no son capaces de comenzar una infección (Cappelier, Besnard, Roche, Velge y Federighi, 2007; Habimana et al., 2014).

Dinu y Bach (2011) observaron que en la superficie de los vegetales, las células de Escherichia coli 0157:H7 eran inducidas al estado VBNC debido a las bajas temperaturas. Sin embargo, estas bacterias ubicadas en la filósfera de la lechuga, seguían siendo metabólicamente activas, ya que fueron capaces de producir pequeñas cantidades de verotoxinas. Posteriormente Van der Linden et al. (2014) demostraron que las células de Escherichia coli 0157:H7 sometidas a determinadas circunstancias de estrés eran capaces de recuperarse y atacar la superficie de la lechuga sobre la que se inocularon. Recientemente Highmore et al. (2018) han puesto de manifiesto que las células de Listeria monocytogenes en el estado VBNC inducido por los tratamientos de cloro que se usan para la desinfección del agua durante el lavado de los vegetales eran capaces de mantener su patogenicidad cuando fueron ingeridas por el nematodo Caenorhabditis elegans. Los investigadores observaron la presencia del patógeno en el lumen intestinal de Caenorhabditis elegans, lo que indica su capacidad de resucitación e invasión celular tras su ingestión. Todos estos es- tudios subrayan el riesgo que pueden representar para la salud pública los patógenos en estado VBNC transmitidos por los alimentos.

\section{5. ¿QUÉ SE SABE DEL ESTADO FISIOLÓGICO DE LAS BACTERIAS EN LOS PRODUCTOS VEGETALES FRESCOS?}

La presencia de bacterias en estado VBNC en muestras ambientales, principalmente en agua, está ampliamente demostrada en la literatura científica (Gensberger et al., 2014; Li et al., 2014; Van Frankenhuyzen, Trevors, Flemming, Lee y Habash, 2013). Sin embargo, pocos estudios se han centrado en evaluar la presencia de células en estado VBNC en el tejido vegetal durante la producción o el procesado. En general, se ha descrito que la presencia de bacterias viables en el tejido vegetal suele estar comprendida entre 1 - 4 unidades logarítmicas superior al número de células cultivables (véase figura 2).

Figura 2. Recuentos de Escherichia coli cultivable (recuento en placa) y de Escherichia coli VBNC (VBNC= células viables-células cultivables) en lechuga baby pigmentada regada con agua de superficie

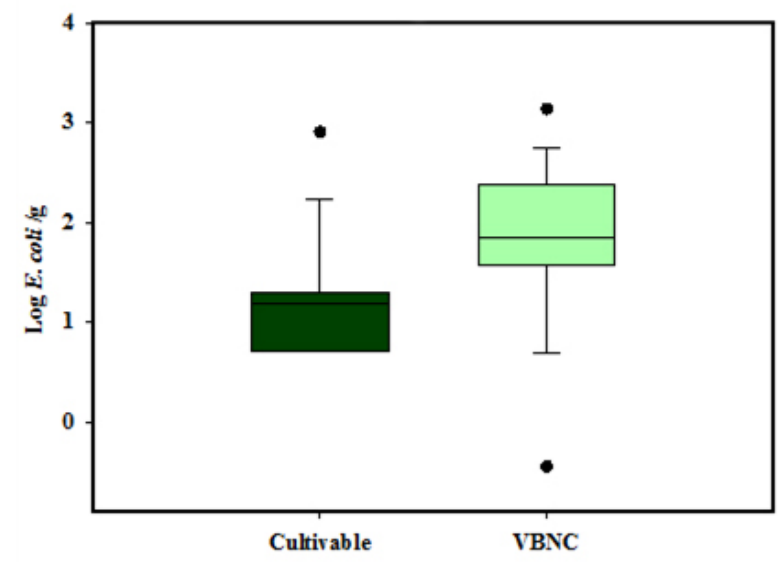

Fuente: elaboración propia

En un estudio en cámaras de cultivo controlado, Moyle et al. (2013) inocularon plantas de lechuga romana con $10^{6} \mathrm{CFU} /$ por hoja de Escherichia coli 0157:H7 y estudiaron su viabilidad durante siete días. La cuantificación de Escherichia coli 0157:H7 con PMA-qPCR y con la técnica de recuento en placa mostró que la mayoría de las células del patógeno presentes en el tejido vegetal se encontraban es estado VBNC. Utilizando la técnica del PMA-qPCR para la cuantificación de células VBNC, Truchado et al. (2016) determinaron que en le- 
chuga iceberg, la concentración de Escherichia coli en estado VBNC era dos unidades logarítmicas superior a la cantidad de Escherichia coli cultivable. La lechuga había sido regada con agua superficial de baja calidad en la que se habían cuantificado $6 \log$ ufc/100 mL de Escherichia coli en estado VBNC y $4 \log$ ufc/100 mL de cultivables. Resultados similares han sido recientemente publicados por Tombini-Decol et al. (2019) en lechuga baby pigmentada regada durante todo su ciclo de cultivo con agua regenerada del tratamiento secundario de la depuradora. Los resultados muestran una diferencia de aproximadamente dos unidades logarítmicas entre los recuentos de Escherichia coli viable y los de Escherichia coli cultivable en el tejido vegetal. La presencia de VBNC presentes en el tejido vegetal fueron atribuidas al estrés medioambiental y al tratamiento de desinfección aplicado al agua de riego.

Estos estudios científicos ponen de manifiesto la relevancia del estado fisiológico de las bacterias en el tejido vegetal, ya que las células en estado VBNC podrían revertir este estado al de cultivable y desarrollar su patogenicidad con el consiguiente riesgo para la salud pública, tal y como se ha indicado anteriormente. Por estas razones, es importante seguir profundizando en el estado fisiológico de las bacterias presentes en los productos vegetales frescos y en cómo las distintas prácticas agrícolas, las condiciones climatológicas y el procesado pueden afectar al estado de las mismas.

\section{BIBLIOGRAFÍA}

Anderson, M., Bollinger, D., Hagler, A., Hartwell, H., Rivers, B., Ward, K. y Steck, T. R. (2004). Viable but nonculturable bacteria are present in mouse and human urine specimens. Journal of Clinical Microbiology, 42 (2), pp. 753-758. https://doi. org/10.1128/jcm.42.2.753-758.2004

Anuchin, A. M., Mulyukin, A. L., Suzina, N. E., Duda, V. I., El-Registan, G. I. y Kaprelyants, A. S. (2009). Dormant forms of Mycobacterium smegmatis with distinct morphology. Microbiology, 155 (4), pp. 1071-1079. https://doi. org/10.1099/mic.0.023028-0

Anvarian, A. H. P., Smith, M. P. y Overton, T. W. (2016). The effects of orange juice clarification on the physiology of Escherichia coli; growth-based and flow cytometric analysis. International Journal of Food Microbiology, 219, pp. 38-43. https://doi.org/10.1016/j.ijfoodmicro.2015.11.016

Asakura, H., Kawamoto, K., Haishima, Y., Igimi, S., Yamamoto, S. y Makino, S. I. (2008). Differential expression of the outer membrane protein $\mathrm{W}(\mathrm{OmpW})$ stress response in enterohemorrhagic Escherichia coli 0157:H7 corresponds to the viable but non-culturable state. Research in Microbiology, 159 (9-10), pp. 709-717. https:// doi.org/10.1016/j.resmic.2008.08.005

Aurass, P., Prager, R. y Flieger, A. (2011). EHEC/EAEC O104:H4 strain linked with the 2011 German outbreak of haemolytic uremic syndrome enters into the viable but non-culturable state in response to various stresses and resuscitates upon stress relief. Environmental
Microbiology, 13 (12), pp. 3139-3148. https://doi.org/10.1111/j.14622920.2011.02604.x

Ayrapetyan, M., Williams, T. C., Baxter, R. y Oliver, J. D. (2015). Viable but nonculturable and persister cells coexist stochastically and are induced by human serum. Infection and Immunity, 83 (11), pp. 4194-4203. https://doi. org/10.1128/IAI.00404-15

Berney, M., Hammes, F., Bosshard, F., Weilenmann, H. U. y Egli, T. (2007). Assessment and interpretation of bacterial viability by using the LIVE/DEAD BacLight Kit in combination with flow cytometry. Applied Environmental Microbiology, 73 (10), pp. 3283-3290. https://doi.org/10.1128/AEM.02750-06

Besnard, V., Federighi, M. y Cappelier, J. M. (2000). Evidence of Viable but Non-culturable state in Listeria monocytogenes by direct viable count and CTC-DAPI double staining. Food Microbiology, 17 (6), pp. 697-704. https://doi. org/10.1006/fmic.2000.0366

Besnard, V., Federighi, M., Declerq, E., Jugiau, F. y Cappelier, J. M. (2002). Environmental and physico-chemical factors induce VBNC state in Listeria monocytogenes. Veterinary Research, 33 (4), pp. 359-370. https://doi.org/10.1051/vetres:2002022

Bridier, A., Hammes, F., Canette, A., Bouchez, T. y Briandet, R. (2015). Fluorescence-based tools for single-cell approaches in food microbiology. International Journal of Food Microbiology, 213, pp. 2-16. https://doi.org/10.1016/j.ijfoodmicro.2015.07.003
Cappelier, J. M., Besnard, V., Roche, S. M., Velge, P. y Federighi, M. (2007). Avirulent viable but non culturable cells of Listeria monocytogenes need the presence of an embryo to be recovered in egg yolk and regain virulence after recovery. Veterinary Research, 38 (4), pp. 573-583. https://doi.org/10.1051/ vetres:2007017

Cook, K. L. y Bolster, C. H. (2007). Survival of Campylobacter jejuni and Escherichia coli in groundwater during prolonged starvation at low temperatures. Journal of Applied Microbiology, 103 (3), pp. 573-583. https://doi.org/10.1111/ j.1365-2672.2006.03285.x

Costa, K., Bacher, G., Allmaier, G., Dominguez-Bello, M. G., Engstrand, L., Falk, P., de Pedro, M. A. y García-del Portillo F. (1999). The morphological transition of Helicobacter pylori cells from spiral to coccoid is preceded by a substantial modification of the cell wall. Journal of Bacteriology, 181 (12), pp. 3710-3715. https://doi.org/10.1128/ JB.181.12.3710-3715.1999

Cunningham, E., O’Byrne, C. y Oliver, J. D. (2009). Effect of weak acids on Listeria monocytogenes survival: evidence for a viable but nonculturable state in response to low pH. Food Control, 20 (12), pp. 1141-1144. https://doi. org/10.1016/j.foodcont.2009.03.005

Day, A. P. y Oliver J. D. (2004). Changes in membrane fatty acid composition during entry of Vibrio vulnificus into the viable but non-culturable state. Journal of Microbiology, 42 (2), pp. 69-73. 
Ding, T., Suo, Y., Xiang, Q., Zhao, X., Chen, S., Ye, X. y Liu D. (2017). Significance of viable but nonculturable Escherichia coli: induction, detection, and control. Journal of Microbiology and Biotechnology, 27 (3), pp. 417-428. https://doi. org/10.4014/jmb.1609.09063

Dinu, L. D. y Bach, S. (2011). Induction of viable but nonculturable Escherichia coli 0157:H7 in the phyllosphere of lettuce: a food safety risk factor. Applied Environmental Microbiology, 77 (23), pp. 8295-8302. https://doi.org/10.1128/ AEM.05020-11

EFSA Panel on Biological Hazards (BIOHAZ). (2013). Scientific Opinion on the Risk Posed by Pathogens in Food of Non-animal Origin. Part 1 (outbreak data analysis and risk ranking of food/ pathogen combinations). EFSA Journal, 11 (1), 3025. https://doi.org/10.2903/j. efsa.2013.3025

Elizaquível, P., Sánchez, G. y Aznar, R. (2012). Quantitative detection of viable foodborne E. coli 0157:H7, Listeria monocytogenes and Salmonella in freshcut vegetables combining propidium monoazide and real-time PCR. Food Control, 25 (2), pp. 704-708. https://doi. org/10.1016/j.foodcont.2011.12.003

Fakruddin, M, Bin Mannan, K. S. y Andrews, S. (2013). Viable but Non culturable Bacteria: Food Safety and Public Health Perspective. ISRN Microbiology, 2013, 703813. https://doi. org/10.1155/2013/703813

Fang, J., Wu, Y., Qu, D., Ma B., Yu X., Zhang, M. y Han, J. (2018). Propidium monoazide Real-time loop-mediated isothermal amplification for specific visualization of viable Salmonella in food. Letters in Applied Microbiology, 67 (1), pp. 79-88. https://doi.org/10.1111/lam.12992

Fischer-Le Saux, M., Hervio-Heath, D., Loaec, S., Colwel, R. R. y Pommepuy, M. (2002). Detection of cytotoxin-hemolysin mRNA in nonculturable populations of environmental and clinical Vibrio vulnificus strains in artificial seawater. Applied Environmental Microbiology, 68 (11), pp. 5641-5646. https://doi.org/10.1128/ AEM.68.11.5641-5646.2002

Fittipaldi, M., Nocker, M. A. y Codony, F. (2012). Progress in understanding preferential detection of live cells using viability dyes in combination with DNA amplification. Journal Microbiology Methods, 91 (2), pp. 276-289. https:// doi.org/10.1016/j.mimet.2012.08.007
Gensberger, E. T., Polt, M., Konrad-Köszler, M., Kinner, P., Sessitsch, A. y Kostic, T. (2014). Evaluation of quantitative PCR combined with PMA treatment for molecular assessment of microbial water quality. Water Research, 67, pp. 367-376. https://doi.org/10.1016/j.watres.2014.09.022

Habimana, O., Nesse, L. L., Møretrø. T., Berg, K., Heir, E., Vestby, L. K. y Langsrud. S. (2014). The persistence of Salmonella following desiccation under feed processing environmental conditions: a subject of relevance. Letters in Applied Microbiology, 59 (5), pp. 464-470. https://doi.org/10.1111/lam.12308

Highmore, C. J., Warner, J. C., Rothwell, S. D., Wilks, S. A. y Keevil, C. W. (2018). Viable-but nonculturable Listeria monocytogenes and Salmonella enterica serovar thompson induced by chlorine stress remain infectious. MBio, 9 (2), e00540-18. https://doi.org/10.1128/ mBio.00540-18

Kana, B. D., Gordhan B. G., Downing K. J., Sung N., Vostroktunova G., Machowski E. E., Tsenova, L., Young, M., Kaprelyants, A., Kaplan, G. y Mizrahi V. (2008). The resuscitation-promoting factors of Mycobacterium tuberculosis are required for virulence and resuscitation from dormancy but are collectively dispensable for growth in vitro. Molecular Microbiology, 67 (3), pp. 672684 . https://doi.org/10.1111/j.13652958.2007.06078.x

Kell, D. B., Kaprelyants, A. S., Weichart, D. H., Harwood, C. R. y Barer, M. R. (1998). Viability and activity in readily culturable bacteria: a review and discussion of the practical issues. Antonie van Leeuwenhoek, 73 (2), pp. 169-187. https://doi. org/10.1023/a:1000664013047

Lai, C. J., Chen, S. Y., Lin, I. H., Chang, C. H. y Wong, H. C. (2009). Change of protein profiles in the induction of the viable but non culturable state of Vibrio parahaemolyticus. International Journal of Food Microbiology, 135 (2), pp. 118 124. https://doi.org/10.1016/j.ijfoodmicro.2009.08.023

Li, D., Tong, T., Zeng, S., Lin, Y., Wu, S. y He, M. (2014). Quantification of viable bacteria in wastewater treatment plants by using propidium monoazide combined with quantitative PCR (PMAqPCR). Journal of Environmental Sciences, 26 (2), pp. 299-306. https://doi. org/10.1016/S1001-0742(13)60425-8
Mascher, F., Hase, C., Moenne-Loccoz, Y. y Défago, G. (2000). The viable-butnonculturable state induced by abiotic stress in the biocontrol agent Pseudomonas fluorescens CHAO does not promote strain persistence in soil. Applied and Environmental Microbiology, 66 (4), pp. 1662-1667. https://doi. org/10.1128/aem.66.4.1662-1667.2000

Makino, S. I., Kii, T., Asakura, H., Shirahata, T., Ikeda, T., Takeshi, K. y Itoh, K. (2000). Does enterohemorrhagic Escherichia coli 0157:H7 enter the viable but non culturable state in salted salmon roe? Applied Environmental Microbiology, 66 (12), pp. 5536-5539. https:// doi.org/10.1128/aem.66.12.55365539.2000

Moyle, A. L., Harris, L. J. y Marco, M. L. (2013). Assessments of total and viable Escherichia coli 0157:H7 on field and laboratory grown lettuce. PLoS One, 8 (7), e70643. https://doi.org/10.1371/ journal.pone. 0070643

Nicolò, M. S. y Guglielmino, S. P. P. (2012). Viable but nonculturable bacteria in food. En Maddock, J. (ed.). Public Health-Methodology, Environmental and Systems Issues. Rjeka: InTech, pp. 189-216.

Nkuipou-Kenfack, E., Engel, H., Fakih, S. y Nocker, A. (2013). Improving efficiency of viability-PCR for selective detection of live cells. Journal of Microbiological Methods, 93 (1), pp. 20-24. https://doi. org/10.1016/j.mimet.2013.01.018

Nocker, A. y Camper, A. K. (2009). Novel approaches toward preferential detection of viable cells using nucleic acid amplification techniques. FEMS. Microbiology Letter, 291 (2), pp. 137-142. https://doi. org/10.1111/j.1574-6968.2008.01429.x

Nyström, T. (2003). Nonculturable bacteria: programmed survival forms or cells at death's door? Bioessays, 25 (3), pp. 204-211. https://doi.org/10.1002/ bies.10233

Oliver, J. D. (2005). The viable but nonculturable state in bacteria. Journal of Microbiology, 43 (1), pp. 93-100.

Oliver, J. D. (2010). Recent findings on the viable but nonculturable state in pathogenic bacteria. FEMS Microbiology Reviews, 34 (4), pp. 415-425. https://doi. org/10.1111/j.1574-6976.2009.00200.x

Pommepuy, M., Butin, M., Derrien, A., Gourmelon, M., Colwell, R. y Cormier, M. (1996). Retention of enteropatho- 
genicity by viable but nonculturable $E s$ cherichia coli exposed to seawater and sunlight. Applied Environmental Microbiology, 62 (12), pp. 4621-4626. https:// doi.org/10.1128/AEM.62.12.46214626.1996

Rastogi, G., Sbodio, A., Tech, J. J., Suslow, T. V., Coaker, G. L. y Leveau J. H. (2012). Leaf microbiota in an agroecosystem: spatiotemporal variation in bacterial community composition on field-grown lettuce. The ISME Journal, 6 (10), pp. 1812-1822. https://doi.org/10.1038/ ismej.2012.32

Sieracki, M. E., Cucci, T. L. y Nicinski, J. (1999). Flow cytometric analysis of 5-cyano-2,3-ditolyl tetrazolium chloride activity of marine bacterioplankton in dilution cultures. Applied Environmental Microbiology, 65 (6), pp. 2409-2417. https://doi.org/10.1128/ AEM.65.6.2409-2417.1999

Signoretto, C., Lleo, M. D. M. y Canepari. P. (2002). Modification of the peptidoglycan of Escherichia coli in the viable but nonculturable state. Current Microbiology, 44 (2), pp. 125-131. https://doi. org/10.1007/s00284-001-0062-0

Tamburini, S., Foladori, P., Ferrentino, G., Spilimbergo, S. y Jousson, O. (2014). Accurate flow cytometric monitoring of Escherichia coli subpopulations on solid food treated with high pressure carbon dioxide. Journal of Applied Microbiology, 117 (2), pp. 440-450. https://doi. org/10.1111/jam.12528

Tombini Decol, L., López-Gálvez, F., Truchado, P., Tondo, E. C., Gil, M. I. y Allende, A. (2019). Suitability of chlorine dioxide as a tertiary treatment for municipal wastewater and use of reclaimed water for overhead irrigation of baby lettuce. Food Control, 96, pp. 186193. https://doi.org/10.1016/j.foodcont.2018.08.036

Truchado, P., Gil, M. I., Kostic, T. y Allende, A. (2016). Optimization and validation of a PMA-qPCR method for Escherichia coli quantification in primary production. Food Control, 62, pp. 150156. https://doi.org/10.1016/j.foodcont.2015.10.014
Van der Linden, I., Cottyn, B., Uyttendaele, M., Vlaemynck, G., Maes, M. y Heyndrickx, M. (2014). Evaluation of an attachment assay on lettuce leaves with temperature and starvation stressed Escherichia coli 0157:H7 MB3885. Journal of Food Protection, 77 (4), pp. 549-557. https://doi.org/10.4315/0362-028X. JFP-13-332

Van Frankenhuyzen, J. K., Trevors, J. T., Flemming, C. A., Lee, $H$. y Habash, $M$. B. (2013). Optimization, validation, and application of a real-time PCR protocol for quantification of viable bacterial cells in municipal sewage sludge and biosolids using reporter genes and Escherichia coli. Journal of Industrial Microbiology and Biotechnology, 40 (11), pp.1251-1261. https://doi. org/10.1007/s10295-013-1319-x

Wan, C., Yang, Y., Xu, H., Aguilar, Z. P., Liu, C., Lai, W., Xiong, Y., Xu, F. y Wei, H. (2012). Development of a propidium monoazide treatment combined with loop-mediated isothermal amplification (PMALAMP) assay for rapid detection of viable Listeria monocytogenes. International Journal of Food Science and Technology. 47 (11), pp. 2460-2467. https://doi. org/10.1111/j.1365-2621.2012.03123.x

Wang, L., Li, P., Zhang, Z., Chen, Q., Aguilar, Z. P. y Xu, H. (2014). Rapid and accurate detection of viable Escherichia coli O157: H7 in milk using a combined IMS, sodium deoxycholate, PMA and realtime quantitative PCR process. Food Control, 36 (1), pp. 119-125. https://doi. org/10.1016/j.foodcont.2013.08.011

Winkelströter, L. K. y De Martinis, E. C. P. (2015). Different methods to quantify Listeria monocytogenes biofilms cells showed different profile in their viability. Brazilian Journal of Microbiology. 46 (1), pp. 231-235. https://doi. org/10.1590/S1517-838220131071

Xu, H. S., Roberts, N., Singleton, F. L., Attwell, R. W., Grimes, D. J. y Colwell, R. R. (1982). Survival and viability of nonculturable Escherichia coli and Vibrio cholera in the estuarine and marine environment. Microbial Ecology, 8 (4), pp. 313-323. https://doi.org/10.1007/ BF02010671
Zhang, S., Ye, C., Lin, H., Lv, L. y Yu, X. (2015). UV disinfection induces a VBNC state in Escherichia coli and Pseudomonas aeruginosa. Environmental Science Technology, 49 (3), pp. 1721-1728. https://doi. org/10.1021/es505211e

Zhao, X., Wang, J., Forghani, F., Park J. H, Park M. S, Seo, K. H. y Oh, D. H. (2013). Rapid detection of viable Escherichia coli 0157 by coupling propidium monoazide with loop-mediated isothermal amplification. Journal of Microbiology and Biotechnology, 23 (12), pp. 1708-1716. https://doi.org/10.1128/ AEM.00354-11

Zhao, X., Zhong, J., Wei, C., Lin, C. W. y Ding, T. (2017). Current perspectives on viable but non-culturable state in foodborne pathogens. Frontiers in Microbiology, 8, 580. https://doi.org/10.3389/ fmicb. 2017.00580

Zhou, B., Liang, T., Zhan, Z., Liu, R., Li, F. y $\mathrm{Xu}, \mathrm{H}$. (2017). Rapid and simultaneous quantification of viable Escherichia coli 0157:H7 and Salmonella spp. in milk through multiplex real-time PCR. Journal of Dairy Science, 100 (11), 8804-8813. https://doi.org/10.3168/ jds.2017-13362

\section{Recursos en línea}

Commission Regulation (EC) No 2073/2005 of 15 November 2005 on microbiological criteria for foodstuffs. [En línea]. Disponible en https:// eur-lex.europa.eu/legal-content/ES/ TXT/?uri=celex:32005R2073

European Commission Notice No. 2017/C 163/01 on Guidance Document on Addressing Microbiological Risks in Fresh Fruit and Vegetables at Primary Production through Good Hygiene. [En línea]. Disponible en https://eur-lex.europa. eu/legal-content/EN/TXT/?uri=CELEX\% 3A52017XC0523\%2803\%29

FSMA Final Rule on Produce Safety. Standards for the Growing, Harvesting, Packing, and Holding of Produce for Human Consumption. [En línea]. Disponible en https://www.fda.gov/food/food-safetymodernization-act-fsma/fsma-final-rule-produce-safety 